\title{
CYTOPATHIC EFFECTS OF PATHOGENIC AND NON- PATHOGENIC SPECIES OF CANDIDA ON CULTURED MOUSE EPITHELIAL CELLS: RELATION TO THE GROWTH RATE AND MORPHOLOGY OF THE FUNGI
}

\author{
Rosalinde Hurley and Valerie C. Stanley \\ Department of Bacteriology, Queen Charlotte's Maternity Hospital, London, Institute of \\ Obstetrics and Gynaecology, University of London, and Department of Bacteriology, \\ The Medical School, University of Leeds
}

IN most diphasic fungi there is a morphological distinction between the parasitic and saprophytic modes of growth; the organisms are pathogenic in the tissue yeast (Y) phase, and saprophytic in the mycelial (M) phase. Workers on candidosis have extrapolated from this observation and speculated that pathogenicity in Candida spp. is likely to be related to the phase of growth. As both phases are seen in lesions, each has been stigmatised by different workers as the pathogenic form.

The yeast phase is seen on microscopy of direct films made from healthy body surfaces infected with Candida. Kozinn and Taschdjian (1962), studying gastro-intestinal candidosis, equated the appearance of mycelium in smears of faeces with the signs and symptoms of illness, and Rogers (1957) made similar observations. Mankowski (1963) concluded from experimental studies that the blastosporic phase was the more pathogenic, and Dr Sujata G. Dastidar (1967, personal communication) noted that often only yeasts are seen in direct films made from the lesions of superficial thrush. Both Haley (1965-66) and Rogers (1966) drew attention to the danger of too readily accepting that the appearance of mycelium in clinical specimens denoted a pathological condition, and pointed out that the nature of the specimen itself might promote filamentation.

In previous experiments, Stanley and Hurley (1967) showed that cell culture systems were suitable models for studies of the pathogenic mechanisms of Candida. It is the purpose of this paper to compare the cytopathic effects of pathogenic and non-pathogenic species of Candida on cultured mouse epithelial cells, and to show the relationship between the degree of lethality of the fungi, their growth rates and the morphological phase of growth (see also Stanley, 1968).

MATERIALS AND METHODS

Organisms

The cultures studied belonged to two groups of Candida species: the pathogenic group, which comprised 7 species that have been isolated from human sources, and the nonpathogenic group of 6 species isolated originally from plants, from animals other than man,

Received 12 June 1968; accepted 31 July 1968.

J. MED. MICROBIOL.-VOL. 2 (1969) 
or from inanimate sources. In the pathogenic group were: Candida albicans (1 culture), C. stellatoidea (1), C. krusei (1), C. tropicalis (1), C. pseudotropicalis (1), C. parapsilosis (C. parakrusei) (2) and C. guilliermondii (2); and in the non-pathogenic group were one culture each of $C$. diddensii, $C$. blankii, $C$. ingens, $C$. cacaoi, $C$. kefyri and $C$. shehatae. Although 5 of the cultures in the second group were not assigned specific status by Lodder and Kreger-Van Rij (1967), they are kept as stock cultures by Miss Helen R. Buckley, by whom they were kindly supplied. A culture of Saccharomyces cerevisiae isolated from a vaginal swab was used as a control.

Standard suspensions of fungi $(30,000$ blastospores per $\mathrm{ml})$ were prepared, as described by Stanley and Hurley, in tissue culture growth medium (TCGM), which consisted of "Wellcome" tissue culture medium 199 with the addition of 2 per cent. "Wellcome" calf serum no. 1; they were used to infect tissue cultures and for experiments on growth rates. In tests for pathogenicity, emulsions in saline $(0.85$ per cent. $\mathrm{NaCl})$ were prepared from the overnight growth on glucose peptone agar, and were standardised by counting in a haemacytometer.

\section{Tissue culture}

The methods used for growing mouse renal epithelial cells, for infecting the tissue cultures and for determining the rates of killing of the cultured cells have also been described (Stanley and Hurley). The growth medium in a 5-day-old tissue culture was replaced by the standard suspension of fungus $(30,000$ blastospores per $\mathrm{ml})$, and the preparation was incubated at $37^{\circ} \mathrm{C}$ or at $30^{\circ} \mathrm{C}$. Cultures were examined microscopically at frequent intervals by transmitted light or by phase contrast, and some were stained intravitally. At predetermined intervals, cultures were fixed, stained and examined histologically.

\section{Growth rates of candida cultures}

As the production of mycelium and pseudomycelium by Candida spp. in TCGM made optical density measurements and enumeration by pour plate techniques unsuitable, rates of growth were determined by measurements of dry weight. The yeasts $(10 \mathrm{ml}$ of a suspension in TCGM containing 30,000 blastospores per $\mathrm{ml}$ ) were placed in $\frac{1}{2} \mathrm{Oz}$. siliconed and tightly stoppered bottles, and incubated as stationary cultures at $37^{\circ} \mathrm{C}$. This simulated as closely as possible the conditions of growth in infected cultures, except that living cells were absent. At $0,2,4,8,16,24,48$ and $72 \mathrm{hr}$, a drop of 4 per cent. formaldehyde in saline was added to each of two duplicated cultures, and the cultures were stored at $4^{\circ} \mathrm{C}$ when necessary. The growth was washed, resuspended in distilled water, and transferred to aluminium pans previously dried to constant weight. The samples were dried to constant weight in vacuo over $\mathrm{CaCl}_{2}$. All weights were determined on a Mark 1 Microforce balance (C.I. Electronics Ltd).

\section{Antigenic structure of the fungi}

The antigenic structure of the species of Candida was studied by Miss Helen R. Buckley by methods described by Murray and Buckley (1966).

\section{RESULTS}

The distinction noted by Lodder (1934) between "mycelium" and "pseudomycelium" is used in this paper.

$$
\begin{aligned}
& \text { Killing of cultured cells, and relation to the morphology of } \\
& \text { the fungus }
\end{aligned}
$$

The pathogenic group. Observations on the rates of killing of cultured cells by members of the 7 species in the pathogenic group have been published 
(Stanley and Hurley), and will be summarised briefly. The following stages in the process of degeneration of the cells were recognised.

Stage 1. Minimal degeneration. Mitotic figures present.

Stage 2. Early degeneration. Mitotic figures present.

$2 a$. Less than 5 per cent. degeneration; occasional rounded, swollen cells; occasional pyknosis.

2b. 5-25 per cent. degeneration; focal aggregates of cells at various stages of degeneration and pyknotic, shrunken, clumped cells; no obvious change in remainder of monolayer.

Stage 3. Subtotal degeneration. Mitotic figures absent.

$3 a$. Focal destruction of $25-50$ per cent. of the monolayer; aggregates of degenerate and pyknotic, shrunken cells; remainder of monolayer intact and viable, with normal appearance.

$3 b$. Focal destruction of more than 50 per cent. of the monolayer; patches consisting of viable cells with normal appearance remain.

$3 c$. Generalised degeneration; about 50 per cent. of the cells are at various stages of degeneration with slightly or strongly pyknotic nuclei; karyorrhexis frequent. Degenerate cells interspersed with viable cells and no focal degeneration. Cytoplasm of many cells granular or patchily staining, and cell membrane often conspicuous.

Stage 4. Total degeneration. Large clumps of strongly pyknotic, shrunken cells with eosinophilic cytoplasm. Much of the monolayer has retracted from the glass. Abundant cellular debris.

The rate of destruction of the tissue cells varied with the species of Candida, and the species were separated into groups 1,2 and 3 according to the time of appearance of the cytopathic effects (Stanley and Hurley). Those species regarded from other evidence as the more pathogenic destroyed the cultures most rapidly. There was also a relation between the time of onset and of completion of degeneration and the morphological form of the fungi (table I).

C. albicans, C. stellatoidea and C. tropicalis all produced " germ tubes" and formed relatively more mycelium and less pseudomycelium than did C. krusei, C. pseudotropicalis and C. parapsilosis. C. guilliermondii produced only scanty pseudomycelium and $S$. cerevisiae produced blastospores only. The fungi producing most mycelium (group 1: C. albicans, C. tropicalis, C. stellatoidea) induced degenerative changes rapidly, and totally destroyed the cultures in $24 \mathrm{hr}$. Those producing a lesser amount of mycelium (group 2: C. krusei, C. pseudotropicalis, C. parapsilosis) totally destroyed the tissue cells in $48-72 \mathrm{hr}$, and $C$. guilliermondii, which produced occasional mycelium in tissue culture but not in the control medium, destroyed the cell cultures slowly and less extensively, though still more completely than the control yeast, $S$. cerevisiae, which produced blastospores only. All 7 species produce abundant blastospores.

The non-pathogenic group. Tissue cultures were infected with members of the 6 non-pathogenic species and were incubated in parallel at $37^{\circ} \mathrm{C}$ and at $30^{\circ} \mathrm{C}$. Two temperatures of incubation were used because some of these fungi are near their maximum growth temperatures at $37^{\circ} \mathrm{C}$. Epithelial cell cultures can be maintained at $30^{\circ} \mathrm{C}$, and mitotic figures are seen. The effect of temperature on the relative preponderance of the morphological forms of the fungi could also be studied. 


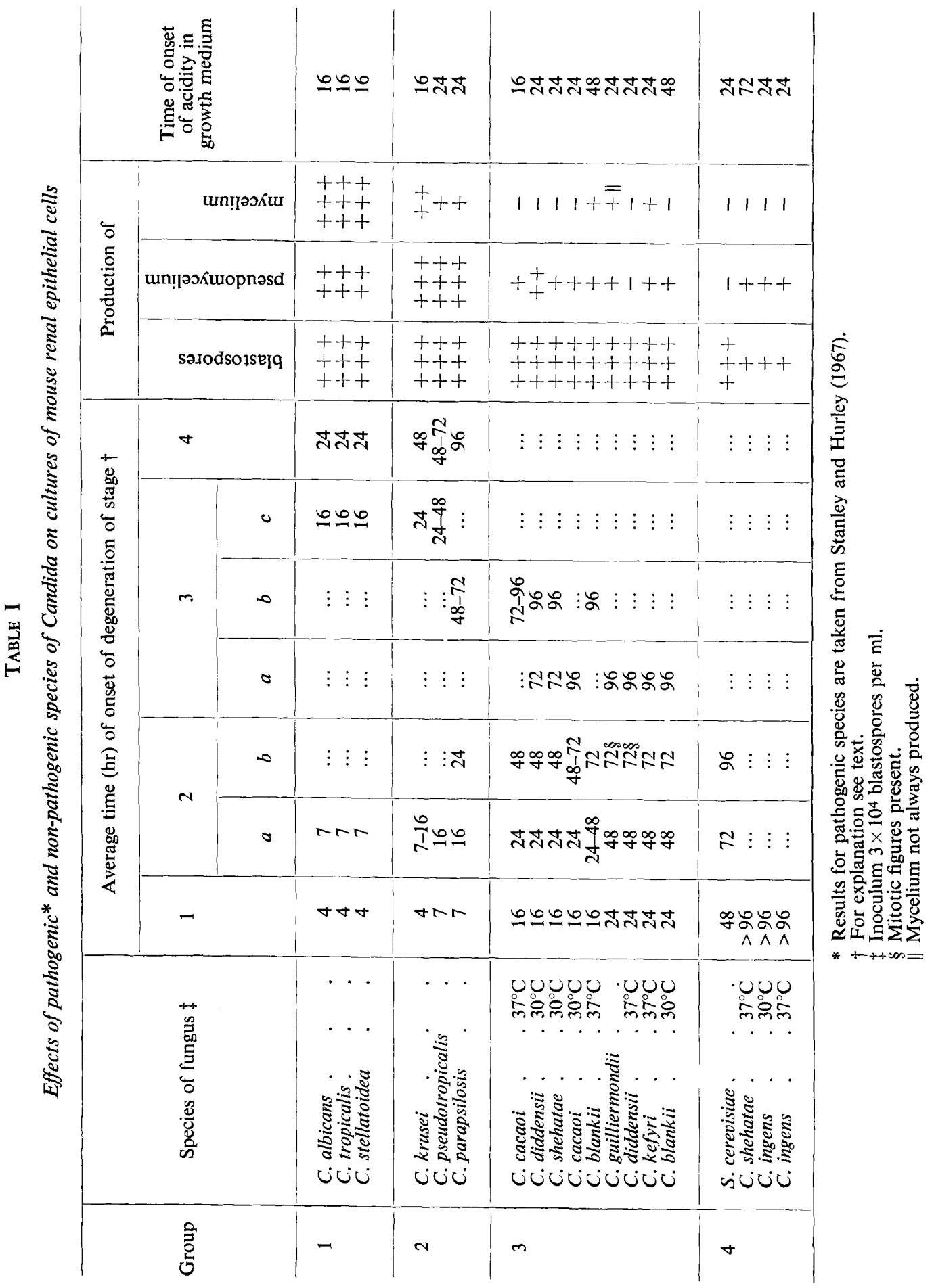


Observations on these cultures are summarised in table I, in which the fungi are listed in descending order according to the rate at which they destroyed the cell cultures. Members of the non-pathogenic group did not have such a rapid action as did the 6 pathogenic species in groups 1 and 2. None of them destroyed the tissue cultures completely within the period of the experiment, and their cytopathic effects were of a different type from those observed in cultures infected with the pathogenic fungi. With fungi in groups 1 and 2 , the cytopathic effects developed diffusely throughout the whole monolayer, which remained largely intact until pyknosis and degeneration were well advanced, but the mitotic figures disappeared early. A different effect was observed in cultures infected with most of the non-pathogenic candidas and with $C$. guilliermondii. The necrotic effects were localised, so that small areas of the monolayer became pyknotic, then clumped and disintegrated. These small areas of focal degeneration were surrounded by sheets of healthy, viable cells of normal appearance in which mitotic figures were still observed until destruction of the monolayer was well advanced . Later, the areas of focal degeneration increased in number and size, but even when 75 per cent. or more of the monolayer was totally destroyed patches of healthy, viable cells remained. Fungi that produced these changes were placed in group 3 .

From table I it can be seen that members of group 3, which includes most of the non-pathogenic species, had a similar action on epithelial cell cultures, and that $C$. guilliermondii falls within this group. C. parapsilosis, although placed in group 2, produced cytopathic effects intermediate in type between those of groups 2 and 3 . C. cacaoi at $30^{\circ} \mathrm{C}$ and at $37^{\circ} \mathrm{C}$, C. shehatae and C. diddensii at $30^{\circ} \mathrm{C}$ and $C$. blankii at $37^{\circ} \mathrm{C}$ caused slightly more rapid destruction of the cell cultures than did C. guilliermondii. C. diddensii and C. kefyri, at $37^{\circ} \mathrm{C}$ and C. blankii at $30^{\circ} \mathrm{C}$ behaved like C. guilliermondii. C. guilliermondii and $C$. diddensii at $37^{\circ} \mathrm{C}$, however, differed from the other members of group 3 in that the disappearance of mitotic figures occurred when only a small proportion of the monolayer had been destroyed. C. shehatae at $37^{\circ} \mathrm{C}$ and $C$. ingens at both temperatures of incubation had no effect on the cell cultures during the period of observation; along with $S$. cerevisiae, which produced relatively slight degeneration on prolonged incubation, they were placed in group 4.

All species in the non-pathogenic group, except $C$. diddensii at $37^{\circ} \mathrm{C}$, produced some pseudomycelial filaments, but growth was predominantly blastosporic. Occasional fine freely branched mycelium was seen only with C. blankii and C. kefyri. After 24 hours' incubation the monolayers were still healthy apart from some early degeneration with C. cacaoi at $30^{\circ} \mathrm{C}$ and at $37^{\circ} \mathrm{C}$, $C$. diddensii and $C$. shehatae at $30^{\circ} \mathrm{C}$ and $C$. blanki at $37^{\circ} \mathrm{C}$. As with the pathogenic species there was ingestion of blastospores by the occasional, scattered macrophages present in the cultures, although this was rare with C. ingens, possibly because of its large size $(15-28) \times(5-10) \mu \mathrm{m}$. Intracellular multiplication of fungi within the macrophages occurred with all species but particularly with $C$. cacaoi, C. blankii, C. kefyri and C. diddensii. Filaments grew out of the infected macrophages, and this was more apparent as the 
incubation time was prolonged. Although $C$. shehatae produced filaments, the ingested blastospores were frequently lysed within cells at $37^{\circ} \mathrm{C}$, and fairly numerous macrophages containing yeast-shaped vacuoles, or very weakly staining yeasts, were seen. With all species, intracellular yeasts were also seen in the epithelial cells; they were surrounded by a non-staining halo, and their position within the monolayer was not constantly related to the presence of

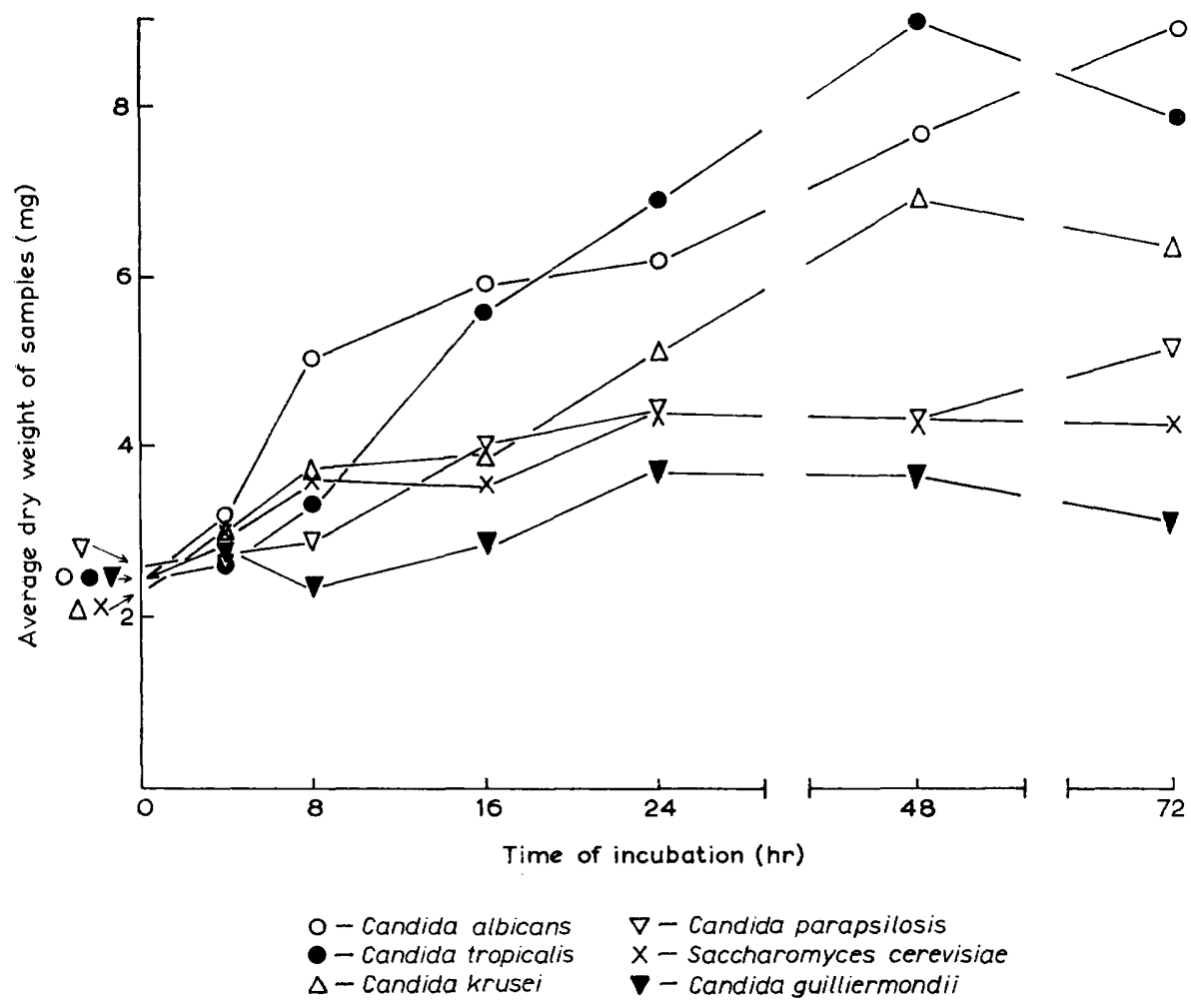

FIGURE. - Growth curves of Candida cultures in medium 199 containing 20 per cent. calf serum a $37^{\circ} \mathrm{C}$, plotted from the average dry weight of 4 samples.

In all cases the initial inoculum concentration was $3 \times 10^{4}$ blastospores per $\mathrm{ml}$.

mycelium or pseudomycelium. Invasion of the epithelial cells by filaments occurred, but was infrequent. C. cacaoi and C. blankii showed essentially similar morphology at $30^{\circ} \mathrm{C}$ and at $37^{\circ} \mathrm{C}$, but the rate of killing was faster at $37^{\circ} \mathrm{C}$, which was nearer to their maximum temperature for growth. C. shehatae, on the other hand, killed cells faster at $30^{\circ} \mathrm{C}$, as did $C$. diddensii, which produced filaments at this temperature. C. ingens and $C$. shehatae at $37^{\circ} \mathrm{C}$ (group 4) had little effect on the tissue cells, and we believe that this was due to poor growth at this temperature and to the ingestion and lysis of blastospores by macrophages present in the culture, with consequent reduction of the effective inoculum. 


\section{Tests for pathogenicity}

Since some of the fungi of the non-pathogenic group closely resembled $C$. guilliermondii and, to a lesser extent, $C$. parapsilosis in their qualitative behaviour towards cultured cells, two of them, $C$. diddensii and $C$. kefyri, were selected for further study. Each was injected intravenously into 6 rabbits in doses of 200 million organisms. Blood cultures at monthly intervals were negative and the animals showed no signs of illness. Yeasts were not cultured from random urine samples. The animals were killed after $6 \mathrm{mth}$, and the tissues were cultured and examined histologically post mortem. No fungi were grown, and there was no morbid anatomical evidence of fungal disease. Further tests are in progress.

\section{Growth rates in the pathogenic Candida species and in $S$. cerevisiae}

The growth rates of one culture each of C. albicans, C. tropicalis, C. krusei, $C$. parapsilosis, C. guilliermondii and $S$. cerevisiae were measured in duplicate on two occasions. Similar results were obtained in the two experiments. The mean constant dry weights of 4 replicate cultures in the two experiments are plotted against the incubation time in hours to give growth curves (figure).

The weight of the initial inoculum was closely similar for all the cultures. C. albicans and $C$. tropicalis (group 1) showed the greatest and most rapid weight gain. With $C$. albicans, the period of most rapid increase was between the 4th and the 8th hr, but the weight of growth continued to rise steadily throughout the remainder of the experiment. With $C$. tropicalis, the onset of rapid weight gain occurred about $4 \mathrm{hr}$ later than with $C$. albicans and the period of maximum increase in weight occurred between the 8th and the 16th hr. The maximum weight was reached at $48 \mathrm{hr}$ and then the fungal weight began to decrease. C. krusei and C. parapsilosis (group 2) showed an intermediate weight gain, but in $C$. krusei the rate of weight increase was faster than in C. parapsilosis after the first $24 \mathrm{hr}$. With both species the amount of growth produced at $24 \mathrm{hr}$ was similar, but was less than with $C$. albicans or $C$. tropicalis. Between the 24th and the 48th hr C. krusei showed a weight increase of about 30 per cent. to its maximum weight, whereas $C$. parapsilosis showed a smaller increase (c. 18 per cent.) between the 24 th and the $72 \mathrm{nd} \mathrm{hr}$. With C. guilliermondii (group 3) there was a long lag period of about $8 \mathrm{hr}$. The weight then increased to a maximum at $24 \mathrm{hr}$; it remained stationary for $24 \mathrm{hr}$, and then began to fall off. Despite the apparently poor growth of this species, microscopic examination of infected epithelial cell cultures showed heavy budding of the fungus.

The behaviour of $S$. cerevisiae, the control yeast, was similar to that of C. guilliermondii, although a greater maximum weight was achieved and there was a more rapid onset of weight increase. The maximum weight gain was of the order of four-fold for C. albicans and C. tropicalis, three-fold for C. krusei and two-fold for C. parapsilosis, C. guilliermondii and S. cerevisiae. 


\section{DisCUSSION}

The fungi with the most rapid and extensive lethal effects on the cultures, that is, the 3 organisms of group 1, C. albicans, C. tropicalis and C. stellatoidea, produce "germ-tubes" and abundant mycelium; formation of pseudomycelium is not so heavy as in some other species. The fungi of group 2, C. krusei, C. pseudotropicalis and C. parapsilosis, produce an intermediate quantity of mycelium and abundant pseudomycelium, and are more slowly lethal. Group-3 fungi destroy cultured cells even more slowly, and include C. cacaoi, C. diddensii, C. blankii, C. guilliermondii, C. kefyri and C. shehatae (the last at $30^{\circ} \mathrm{C}$ only); of these, only $C$. blankii and $C$. kefyri produce any mycelium, whilst $C$. guilliermondii produces mycelium occasionally in the presence of mammalian cells. The remaining fungi (group 4), $C$. shehatae (at $37^{\circ} \mathrm{C}$ ) and $C$. ingens (at $30^{\circ} \mathrm{C}$ and $37^{\circ} \mathrm{C}$ ) have no discernible effect on the cultured cells and do not produce mycelium. $C$. diddensii, the only species in which it proved possible to suppress filament formation completely (at $37^{\circ} \mathrm{C}$ ), is more destructive to the cultures in the filamentous phase (at $30^{\circ} \mathrm{C}$ ).

It thus seems that there is an association between the production of mycelium and the cytopathic effect of the fungi on the cultured cells. To test this relation further, many attempts were made to suppress the $M$ phase of growth in the cell cultures of fungi of the pathogenic species, and thus to study the effects of pure $\mathrm{Y}$ and pure $\mathrm{M}$ forms. The methods used included sulphurfree culture media, the addition of sugars, insulin, cysteine, glutathione or bile salts, and reduction in the amount and change in the type of serum added. Although it was possible to suppress the $M$ form in control culture media, incubation with mammalian cells in modified media that were not toxic stimulated the $M$ phase of growth. This suggests that cells themselves affect the phase of growth. Filamentation of Candida species, particularly C. albicans, in the presence of serum, is, of course, well known, and is the basis of the "germ tube" test for rapid identification of C. albicans (Taschdjian, Burchall and Kozinn, 1960). By means of organ cultures, Koch (1965) was able to induce filament formation in old stock cultures of Candida spp. including C. albicans, and Mackenzie (1965-66) showed that aqueous extracts of organs, particularly the brain and the kidney, stimulated filament formation in C. albicans. We have found that $C$. guilliermondii produces mycelium in cell cultures but not in the growth medium alone, suggesting that the effect was no+ serum dependent. Extracts of mouse kidney in medium 199, with and without added serum, did not induce the formation of mycelium in $72 \mathrm{hr}$, and this suggests that the presence of intact cells was the operative factor in our experiments. It thus seems that mammalian tissues or their aqueous extracts actively promote growth of some of these fungi in the filamentous (M) phase.

Experiments with pathogenic bacteria (Holland and Pickett, 1956; Shepard, 1957; Furness, 1958) have shown a correlation between the growth rate of the bacteria in cell cultures and their pathogenicity. The experiments described in this paper demonstrate that the speed and extent to which cultures of mouse 
renal cells are destroyed are related to the increase in dry weight, which was taken as an index of the rate of growth of the fungi. The speed and extent of destruction of the cell cultures is also correlated with the amount of mycelium produced in the infected cultures (Stanley and Hurley, 1967).

Cantrell and Widra (1964) concluded that unrestricted growth of $C$. albicans in vivo is associated with the $\mathrm{M}$ phase, and our experiments, conducted in vitro with a model resembling conditions in vivo, confirm this view. The cytopathic effects of the candidas are a function of their growth rate and the mycelial phase predominates in the more rapidly growing species. Species such as $C$. albicans and $C$. tropicalis that show the earliest and most rapid weight increase also produce the most abundant mycelial growth and destroy the cell cultures considerably faster than a species such as $C$. guilliermondii, which grows slowly and rarely produces mycelial filaments.

Though this suggests that pathogenicity in Candida is closely related to the rate of mycelial proliferation, the cytopathic effect is not solely a function of the weight of infection. Although the more rapidly lethal species all attain a dry-weight increase of approximately 150 per cent. over the period required for total destruction of the cell cultures (see table II), there is no close correlation between the actual mass attained by the different fungi and the extent of their effect on the cell cultures, e.g., C. parapsilosis and $S$. cerevisiae at $24 \mathrm{hr}$ and at $48 \mathrm{hr}$ have a closely similar dry weight, but $C$. parapsilosis at this time has already caused considerable destruction of the cell cultures and $S$. cerevisiae has had no discernible effect. Similarly, $S$. cerevisiae produces an earlier and greater dry-weight gain than does $C$. guilliermondii although the latter species causes more rapid cytopathic effects. However, for individual fungal species, the time of onset and extent of the cytopathic effects are dependent upon the mass of fungal inoculum (Stanley and Hurley).

The period of maximum increase in dry weight is not correlated with the period of maximum rate of destruction of the cultured epithelial cells, although it corresponds fairly closely to the period of onset of cytopathic effects (stages 1 and 2) in all the Candida species but not in S. cerevisiae (table II). This period is not associated with any particular phase of growth.

It was thought that autolysing the cells of the fungi might release substances toxic to the cultured mammalian cells, but a comparison of the figure with table II shows that there was no correlation between the extent of degeneration in the tissue cultures and a falling off in the dry weight of the fungi. C. albicans, $C$. tropicalis, $C$. krusei and $C$. parapsilosis were still growing well when the cell cultures were completely destroyed. $C$. guilliermondii and $S$. cerevisiae, however, were apparently dying off as the cytopathic effects were becoming more marked. Five-day cell-free culture filtrates of these and other Candida species possessed no toxic activity for mouse renal cell cultures (Stanley and Hurley).

These findings suggest that the cytopathic effects depend upon specific aggressive mechanisms that are possessed to a high degree by species such as C. albicans and $C$. tropicalis and to a low degree by species such as $C$. guilliermondii and other group 3 species. 


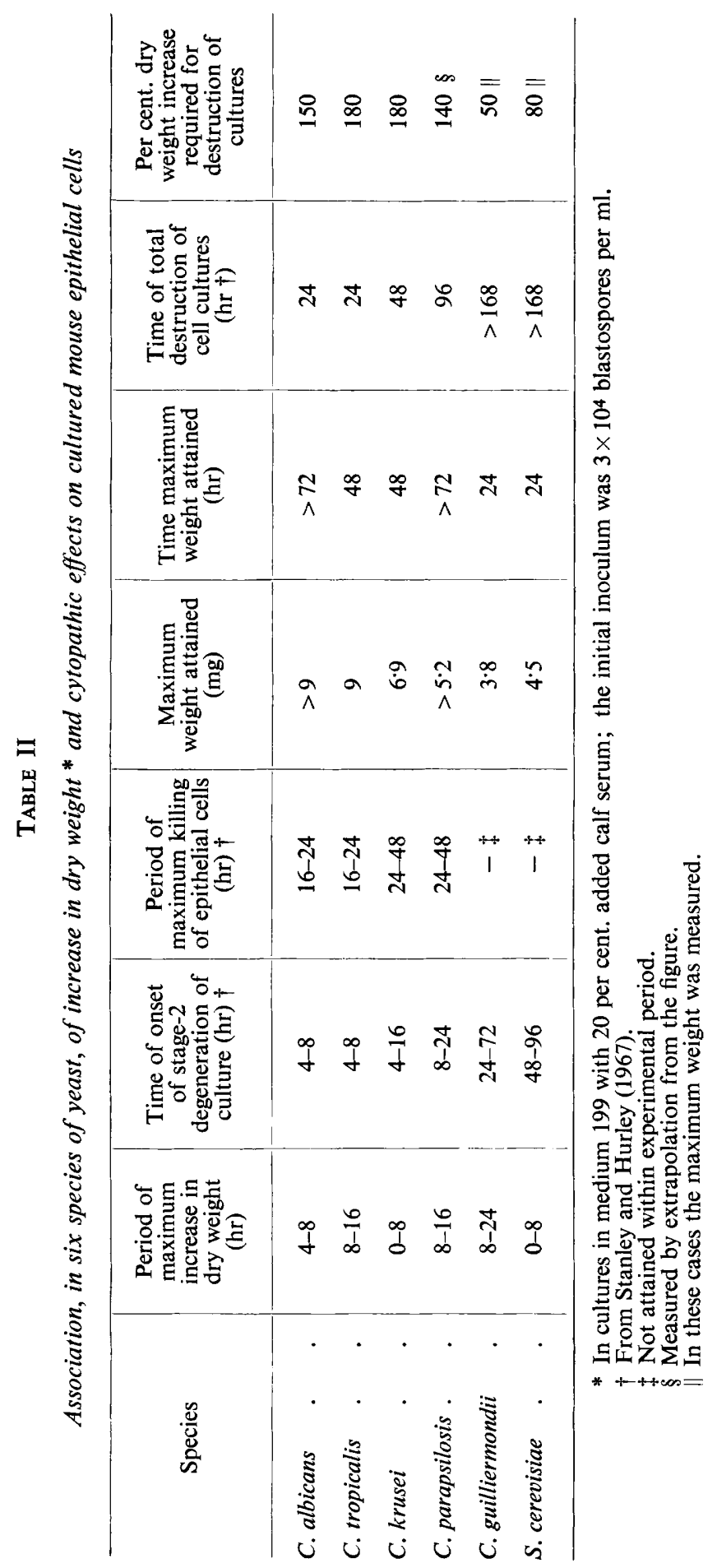


Weyman-Rzucidło (1965) suggested that virulence might be associated with the possession of specific antigens. Isenberg, Allerhand and Berkman (1963) noted immunological differences between mouse virulent and mouse non-virulent $C$. albicans and isolated toxic antigens from the virulent strains. There is no ready correlation between the antigenic structure of our cultures, as studied by Buckley, and their effects on cultured cells, but some of the more destructive of the non-pathogenic species are closely related to the pathogenic species; for example, $S$. kefyri Beijerinck (1889) is classified by Lodder and Kreger-Van Rij (1967) as C. pseudotropicalis var. lactosa. Our strain of C. kefyri is a subculture of the Beijerinck isolate.

The correlation of severe cytopathic effects with rapid growth in the mycelial phase may demonstrate the importance of the $M$ phase in the genesis of infections with Candida spp., but cannot be taken as evidence that the $\mathrm{M}$ phase possesses aggressive mechanisms that are lacking in the $\mathrm{Y}$ phase. The present experiments and others in progress indicate that living cells are parasitised by candidas in two ways; the cells may engulf the yeast form, or they may be invaded by the filamentous form. Death of the cells is the result in either event, but the speed and extent of destruction of cultures is proportional to the amount of fungus produced. The ingested blastospores of most candidas develop intracellular filaments that eventually rupture the cell, but cells heavily parasitised by the blastospores of $C$. diddensii also die, despite the lack of filament formation. In non-pathogenic species such as $C$. ingens and C. shehatae, ingested blastospores are frequently lysed. Our experiments do not, therefore, demonstrate a qualitative difference between the cytopathic effects of $\mathrm{M}$ or $\mathrm{Y}$, but they do demonstrate a relation between cytopathogenicity and the rate of growth. Rapid growth seems to be associated with the $M$ phase, and with mycelium-producing rather than with pseudomyceliumproducing species.

The presence of intact mammalian cells encourages filamentation, and this suggests that the presence of mycelium in direct smears (Rogers, 1957, 1966; Kozinn and Taschdjian, 1962) may denote that the fungi have been exposed to cellular exudates or transudates. It is possible that the sequence of events in vivo parallels that of the experimental system: the $\mathrm{Y}$ phase may initiate infection, thus accounting for the observation of pure Y-phase candidas in some films from candida lesions (Dr Sujata G. Dastidar, 1967, personal communication); and cellular damage may encourage filamentation, the presence of filaments being associated with a more exudative and less superficial type of lesion.

\section{SUMMARY}

The cytopathic effects of standard inocula $(30,000$ blastospores per $\mathrm{ml})$ of Candida albicans, C. tropicalis, C. stellatoidea, C. krusei, C. pseudotropicalis, $C$. parapsilosis and C. guilliermondii (isolated from man) on murine renal epithelial cells in culture were compared with those of $C$. cacaoi, C. diddensii, C. kefyri, C. blankii, C. ingens and $C$. shehatae (isolated from non-human sources). The nature of the changes in the mammalian cells, and the extent 
of their destruction, were shown to be correlated with the growth rate and with the proportion of mycelium in the growing fungi. The presence of mammalian cells induced filamentous change in some species.

These experiments demonstrate the greater importance of the $M$ phase in the progression of candida lesions, because of the more widespread involvement of cells by organisms with rapid growth rates, but they do not demonstrate a qualitative difference in the cytopathic effects of the $M$ and $Y$ phases. They suggest that in vivo the $\mathrm{Y}$ phase may initiate infection, as it does experimentally, and that the $M$ phase is associated with the more rapidly growing species and with extension of the lesion. The filamentous phase may be induced by exposure of the fungi to cellular exudates or transudates.

The work described in this paper was supported by a grant from the Medical Research Council. We are grateful to Miss Helen R. Buckley for her antigenic analyses of the fungi.

\section{REFERENCES}

Beijerinck, M. W. . . . . . . . 1889. Archs néerl. Sci., 23, 428.

CANTrell, H. F., AND Widra, A. . . 1964. J. Bact., 87, 1532.

Furness, G. . . . . . . . . . . . 1958. J. Infect. Dis., 103, 272.

HAley, LeONOR D. . . . . . . . . . 1965-66. Sabouraudia, 4, 98.

Holland, J. J., and Pickett, M. J. . . 1956. Proc. Soc. Exp. Biol. Med., 93, 476.

IsENBERG, H. D., AlleRHAND, J., AND 1963. Nature, Lond., 197, 516.

BERKMAN, J. I.

КоСH, Н. А. . . . . . . . . . 1965.

Kozinn, P. J., and Taschditan, Claire L. 1962.

LODDER, J. . . . . . . . . . . . . . 1934.

Biologia, Bratislava, 20, 52.

LODDER, J., AND KREGER-VAN RIJ, N. J. W. 1967.

Pediatrics, 30, 71.

Verh. K. Akad. Wet., 2nd Sect., 32, 1.

The yeasts, a taxonomic study, Amsterdam.

MACKenZIE, D. W. R. . . . . . . 1965-66. Sabouraudia, 4, 126.

MANkowski, Z. T. . . . . . . . . . . . 1963. Mycopath. Mycol. appl., 19, 1.

Murray, I. G., AND Buckley, Helen R. 1966. In Symposium on candida infections, ed. by H. I. Winner and Rosalinde Hurley, Edinburgh and London, p. 44.

ROGERS, K. B. . . . . . . . . . . 1957. J. Clin. Path., 10, 406.

1966. In Symposium on candida infections, ed. by $\mathbf{H}$. I. Winner and Rosalinde Hurley, Edinburgh and London, p. 179.

SHEPARD, C. C. . . . . . . . . . . . 1957.

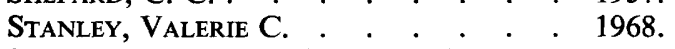

J. Exp. Med., 105, 39.

Stanley, Valerie C., AND Hurley, 1967. Rosalinde

Taschdian, Claire L., Burchall, J. J., 1960. and KozinN, P. J.

Weyman-Rzucidio, Danuta - . . 1965. Acta microbiol. pol., 14, 247.

Ph.D. Thesis, Univ. London.

J. Path. Bact., 94, 301.

Amer. J. Dis. Child., 99, 212. 